\title{
microRNAs regulate TAL1 expression in T-cell acute Iymphoblastic leukemia
}

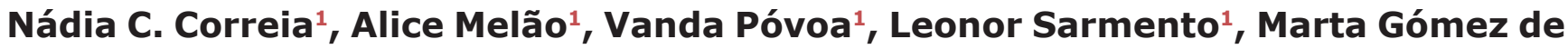 \\ Cedrón'ㄹ, Marcos Malumbres², Francisco J. Enguita ${ }^{1}$, João T. Barata ${ }^{1}$ \\ ${ }^{1}$ Instituto de Medicina Molecular, Faculdade de Medicina, Universidade de Lisboa, Lisboa, Portugal \\ ${ }^{2}$ Cell Division and Cancer Group, Spanish National Cancer Research Centre (CNIO), Madrid, Spain \\ Correspondence to: João T. Barata, e-mail: joao_barata@fm.ul.pt
}

Keywords: T-cell acute lymphoblastic leukemia, T-ALL, TAL1, microRNAs, post-transcriptional regulation

Received: July 27, 2015

Accepted: January 13, 2016

Published: January 23, 2016

\section{ABSTRACT}

The transcription factor TAL1 is a proto-oncogene whose aberrant expression in committed T-cell precursors is associated with the development of T-cell acute lymphoblastic leukemia (T-ALL). The mechanisms leading to aberrant activation of TAL1 in T-ALL patients who lack chromosomal rearrangements involving the TAL1 locus remain largely unknown. We hypothesized that TAL1 levels decrease during normal T-cell development at least in part due to miRNA-dependent silencing, in which case TAL1 over-expression in some T-ALL cases could be the consequence of deregulated miRNA expression. By performing computational prediction of miRNAs that bind to the human TAL1 mRNA we compiled a list of miRNAs that are candidates to regulate TAL1. Using a luciferase reporter system and mutagenesis assays we confirmed the miRNA-TAL1 mRNA interactions and selected candidate miRNAs: miR101, miR-520d-5p, miR-140-5p, miR-448 and miR-485-5p. Over-expression of these microRNAs in different T-ALL cell lines consistently resulted in the down-regulation of TAL1 protein. In accordance, inhibition of miR-101 and miR-520d-5p promoted TAL1 protein expression. Importantly, we found that miR-101, miR-140-5p, miR-448 and miR-485-5p were down-regulated in T-ALL patient specimens and T-ALL cell lines. Our results show for the first time the existence of epigenetic regulation of TAL1 by specific miRNAs which may contribute, at least in part, to the ectopic expression of TAL1 in some T-ALL cases.

\section{INTRODUCTION}

In physiologic conditions, the basic helix-loop-helix transcription factor TAL1 is necessary for hematopoietic commitment [1-3], being expressed very early on in hematopoietic differentiation and silenced during normal T-cell lymphopoiesis from the early thymic progenitor stage onwards [4]. However, TAL1 is ectopically expressed in a majority of childhood T-cell acute lymphoblastic leukemia (T-ALL) cases, with increased TAL1 transcript levels found in more than $60 \%$ of T-ALL patients $[5,6]$ even in the absence of obvious genetic alterations in the gene locus.

TAL1, as other T-cell oncogenes (e.g. HOX11 and LMO2), is commonly found mono or biallelically expressed in T-ALL patient blasts [7]. Either direct cis-activating mechanisms are involved in the gene monoallelic activation or the biallelic expression can be explained by the disruption of trans-acting mechanisms that normally down-regulate TAL1 during T-cell development [7]. The most frequent chromosomal alteration involving the TAL1 locus is the micro-deletion that fuses the TAL1 coding region to the SIL regulatory elements, producing the SIL-TAL1 fusion gene. This alteration occurs in $9-25 \%$ of childhood T-ALLs driving the aberrant monoallelic expression of TAL1 [8]. Recently, it was shown that aberrant expression of TAL1 can result from the formation of cellular contextdependent chromatin loops that mediate cis-activation of the TAL1 locus [9, 10]. Additionally, elegant studies have revealed that micro-insertional mutating events occurring in heterozigosity upstream of the TAL1 
promoter can lead to monoallelic activation of TAL1 $[11,12]$. The exact frequency of TAL1-positive T-ALL cases due to these newly identified events remains to be determined, and thus a fraction of cases with TAL1 monoallelic aberrant expression, as well as those with ectopic biallelic activation, remain to be explained. In this context, regulation by non-coding RNAs (ncRNAs), such as microRNAs (miRNAs) and long non-coding RNAs (lncRNAs) [13] has not yet been thoroughly explored as a possible mechanism of epigenetic regulation of TAL1 expression in physiologic conditions or in malignancy.

MicroRNAs, the most comprehensively studied family of ncRNAs, are small (19-22 nt long), single stranded RNAs involved in post-transcriptional control of gene expression [14-16]. MicroRNAs target proteincoding genes through sequence-specific binding mainly to the 3'-untranslated region (3'UTR) of target messenger RNAs, which in mammals leads mostly to translational repression of the target gene [17]. Several studies [1821] contributed to the notion that specific miRNA gene expression signatures are associated with particular Band T-ALL oncogenetic subgroups. The participation of miRNA genes in T-ALL, individually or within a network, has been explored and specific miRNAs have been implicated in T-ALL pathogenesis [22-26]. Importantly, oncogenes with pivotal roles in the pathogenesis of T-ALL (such as TAL1 [27, 28] and NOTCH1 [29, 30]) have been associated with deregulated miRNA networks in this context.

In the present work, we sought to get further insight into the mechanisms that are involved in aberrant expression of TAL1 in T-ALL and particularly to understand if this process involves miRNAs. We hypothesized that TAL1 levels decrease during normal T-cell development at least in part due to miRNAdependent down-regulation, in which case TAL1 over-expression in some T-ALL cases should be the consequence of deregulated miRNA expression.

\section{RESULTS}

To investigate the existence of post-transcriptional regulation of TAL1 by miRNAs we performed computational prediction of miRNAs that bind to TAL1 3'UTR. Computational algorithms have been the major driving force in predicting miRNA targets [31]. Several web-based bioinformatics tools were used to perform the preliminary identification of putative regulators of TAL1, as detailed in the Methods. The TAL1 3'UTR in humans has around 3.4kb (NM_003189) and harbors a high number of possible miRNA Recognizing Elements (MRE) distributed through the entire sequence (Supplementary Figure 1). From this initial analysis we compiled a list of 90 candidate miRNAs that might regulate TAL1 mRNA (Supplementary Table 1).
Next, we rationally narrowed the list down using the following criteria: a) miRNAs under-expressed in TAL or LMO overexpressing cases (TAL/LMO cytogenetic subgroup, based on primary T-ALL gene expression profiling [23]); b) concomitant identification of LMO2 as putative target, given the frequent aberrant co-expression of both TAL1 and LMO2; c) more than one predicted target site in the 3'UTR of the TAL1 mRNA and/or $8 \mathrm{mer}$ (or 9mer) type of seed paring; d) identification of the miRNA as regulator of TAL1 expression by at least two different algorithms. Any miRNA predicted to fulfill at least one of these criteria was included for further testing. In this way, we narrowed down the list of putative miRNAs targeting TAL1 to 39 (Supplementary Table 2).

In order to validate the candidate miRNA/TAL1 mRNA interaction, we transiently co-transfected 293T cells with a reporter plasmid coding the TAL1 3'UTR immediately downstream of the luciferase open reading frame (pLuc-TAL1-3'UTR), together with the candidate miRNAs from the miR-Vec library [32, 33]. We then verified if the reporter expression was decreased when compared to the control scramble (SCR) sequence, which is indicative of the miRNA biological activity against TAL1 3'UTR (Figure 1A-1D). For further analysis we selected microRNAs that significantly lowered the luciferase expression in 25-50\%: miR-101, miR-520d5p, miR-140-5p, miR-448 and miR-485-5p (see Figure 2 for miRNA binding details). We excluded from further analysis the miR-Vec-20a, miR-Vec-17 and miR-Vec-93, since the miRNAs encoded belong to the oncogenic cluster miR-17-92 (miR-17-5p and miR-20a-5p) or to the same family (miR-93-5p). The cluster miR-17-92 is highly up-regulated in hematopoietic malignancies and has a clearly defined oncogenic function [34-36], which was not consistent with our hypothesis that the candidate miRs should act as tumor suppressor-like genes (by downregulating TAL1). Moreover, we excluded miR-Vec-410 and miR-Vec-199a* due to the weak effect on luciferase expression.

We then mutated the MRE in the 3'UTR of TAL1 in order to disrupt the miRNA/mRNA binding (Figure 2) and re-evaluated the capacity of the respective miRNA to silence the reporter. Mutation of the only binding sequence for miR-101 in TAL1 3'UTR (Figure 2A) fully restored luciferase expression in the presence of the miR-Vec-101 (Figure 3A) demonstrating that the mutated sequence corresponds to the recognizing element of miR-101 in TAL1 3'UTR. The miR-520d-5p has four predicted binding sites in the 3'UTR (Figure 2B) and we were able to mutate three of them. The triple mutants in TAL1 3'UTR did not restore the luciferase expression in the presence of miR-520d (Figure 3B). The miR-520d precursor can give rise to two mature forms of the microRNA, the $5 p$ from the 5' arm of the hairpin and 3p from the 3' arm of the hairpin, both expressed by miR-Vec vectors. The mutation of a putative binding site for miR-520d-3p in the 3'UTR 
(Figure 2C) increased the luciferase expression by $15 \%$ when compared with the non-mutated 3'UTR (Figure 3C), suggesting that the down-regulation of the reporter for miR-520d was partly dependent on the $3 p$ form. Finally, the mutation of one of the three MREs for miR-140-5p (Figure 2D) was sufficient to restore luciferase expression (Figure 3D). This demonstrated that these elements are true recognition sites for miR-140-5p in the TAL1 3'UTR. Mutation of the two putative binding sites for miR-140-3p in the TAL1 3'UTR (Figure 2E) did not significantly affect reporter activity (Figure 3E), showing that the miR-140$3 p$ is not the specimen responsible for the effect of miRVec-140 on the reporter expression.

If a given mRNA is a true target of a specific miRNA, then modulation of the miRNA concentration should result in changes in the amount of protein encoded by the target gene. Thus, in order to evaluate the physiological importance of the miRNA/TAL1 mRNA pairs we over-expressed the candidate miRNAs in T-ALL cell lines that endogenously over-express TAL1, followed by evaluation of endogenous TAL1 mRNA and protein levels. Over-expression of miR-520d, miR-101, miR140, miR-485 and miR-448 in different T-ALL cell lines resulted in down-regulation of TAL1 transcript (Figure 4A) and/or protein (Figure 4B-4C) expression levels in a range of $20-60 \%$. This range is in accordance to the predicted effects of miRNAs in protein expression $[37,38]$ and it varies depending on the cell line and miRNA specimen. Down-regulation mediated by these miRNAs in the TAL1 transcript was observed for miR-520d, miR-101, miR-140 and miR-448 in PF-382 cells and for miR-520d and miR140 in SUP-T1 cells (Figure 4A). Why this heterogeneity occurs amongst T-ALL cell lines, and what it might inform on how TAL1 is regulated by miRNAs, requires further investigation. In any case, these results show that ectopic expression of the selected miRNAs can target TAL1 by affecting the mRNA stability and/or impairing the protein translation in the T-ALL cell lines analyzed.

To complement the previous experiment, we transfected cells with high endogenous miRNA levels and correspondingly low TAL1 expression, with antisense oligoribonucleotides (ASO) to inhibit the function of the endogenous mature miRNAs and evaluate their impact on TAL1 expression. We verified that inhibition of miR-520d-5p and miR-101 rescued endogenous TAL1 protein expression by 20 to $40 \%$ on average (Figure 5A$5 \mathrm{~B})$. This increase in protein expression was not always accompanied by a TAL1 transcript increase (Figure 5C), in accordance with the previous experiments. Therefore, miR-520d-5p and miR-101 affect TAL1 mostly at the level of translation in T-ALL cells.

Subsequently, we compared the expression of the miRNAs between TAL1-positive and -negative T-ALL cell lines and verified that they were (miR-101, 520d$5 p$ ) or tended to be (miR-140-5p and miR-448; not reaching statistical significance), more expressed in the TAL1-negative cell lines. These observations favor our hypothesis that TAL1 over-expression in some T-ALL cases may result from, or be potentiated by, decreased expression of specific miRNAs (Figure 6A). This idea was further strengthened by the fact that these miRNA genes were expressed in normal human thymic populations and that their expression was modulated during T-cell differentiation (Figure 6B).
A

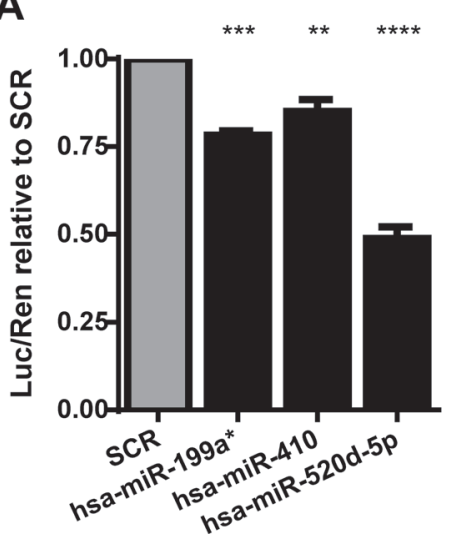

B

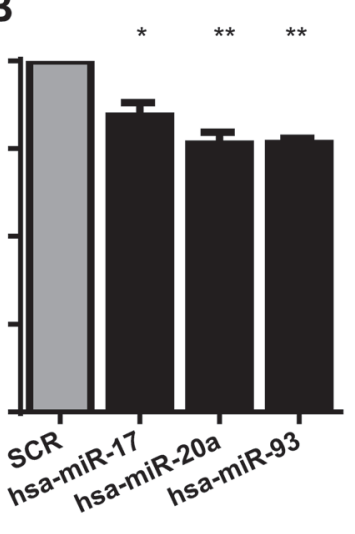

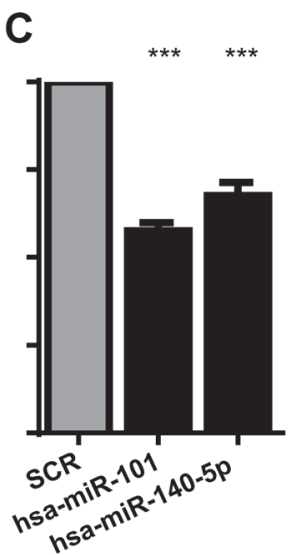

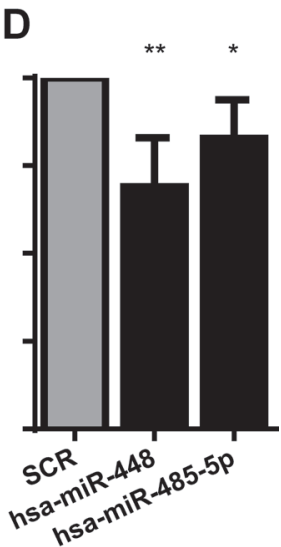

Figure 1: MicroRNAs identified as down-regulating TAL1 3'UTR reporter. The ability of miRNAs to directly target TAL1 was evaluated using a reporter construct carrying the TAL1 3'UTR downstream of the luciferase gene. Results depict only the miRNAs that originated significant differences as compared to scramble sequence, to which all results have been normalized. miRNAs predicted to target TAL1 were 'short-listed' based on the following non-exclusive criteria: A. under-expressed in TAL1/LMO cytogenetic subgroup; B. predicted to also target LMO2; C. with more than one predicted target site and/or 8mer (or 9mer) type of seed paring; D. predicted to target TAL1 by at least two different prediction algorithms. The graphs represent at least two independent experiments with two replicates; statistical analysis was performed by One-way ANOVA $(* \mathrm{p}<0.05 ; * * \mathrm{p}<0.01 ; * * * \mathrm{p}<0.001)$. 
A

8 mer

position 3203-3231

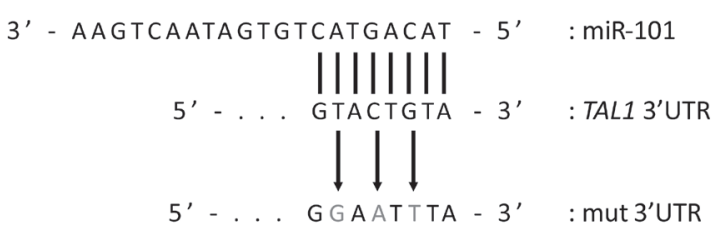

B

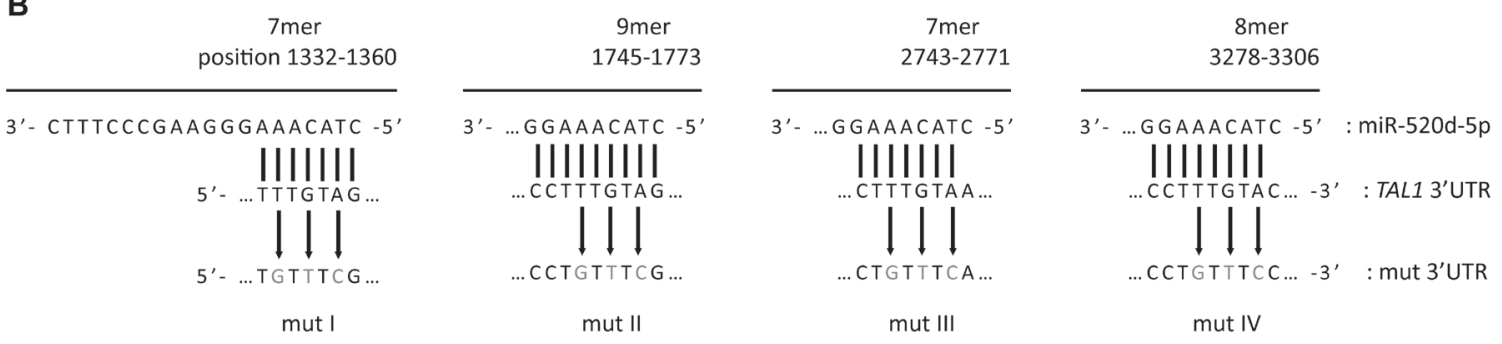

C

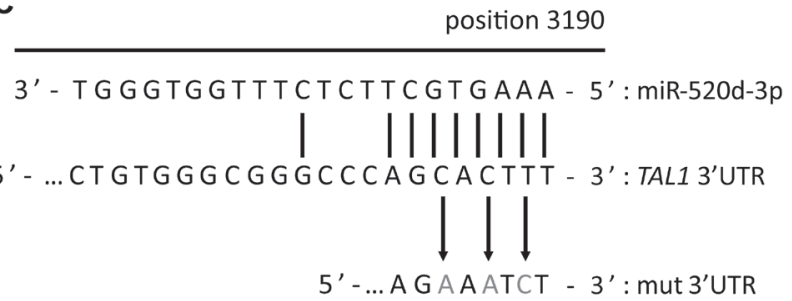

D

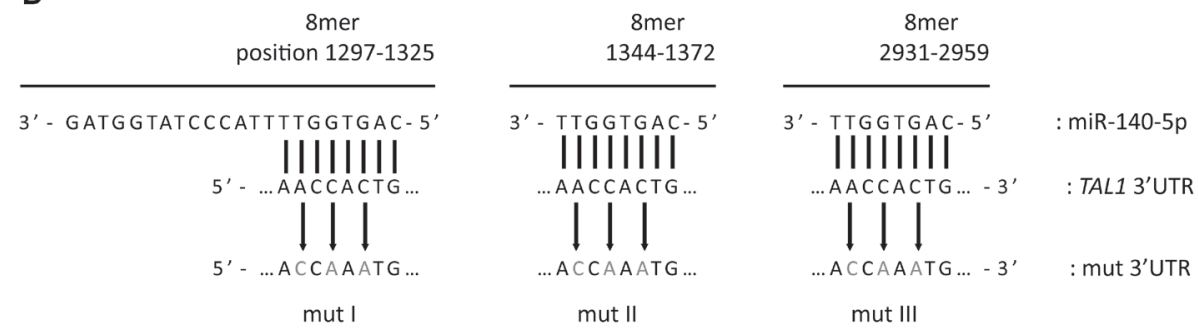

E

position 1390

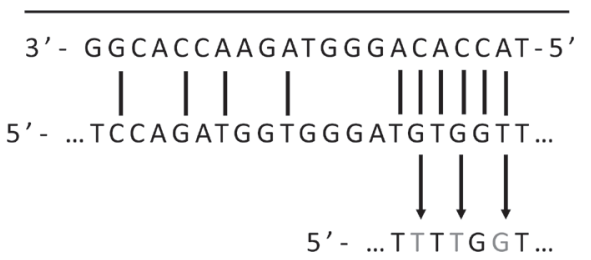

$\mathbf{F}$

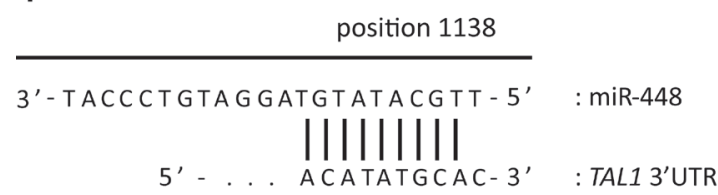

position 3336

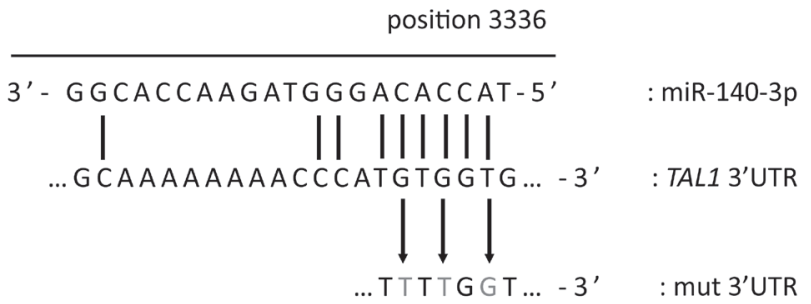

G

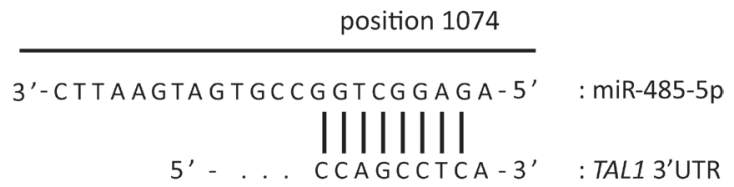

Figure 2: Schematic representation of microRNAs binding to TAL1 3'UTR and respective mutagenesis performed to disrupt miRNA seed binding. Details of binding of A. miR-101; B. miR-520d-5p and D. miR-140-5p to TAL1 3'UTR are depicted according to DianaMicroT [71] target prediction algorithm. The miRNAs miR-520-3p C. and miR-140-3p E. are not predicted to bind to TAL1 3'UTR, nevertheless the putative MRE were mutated as depicted. The nucleotides altered in the mutagenesis assays are depicted in grey. F. miR-448 and G. miR-485-5p binding to TAL1 3'UTR details are depicted according to microRNA.org [68-70] target prediction algorithm. 
We then reasoned that if these miRNAs play a role in TAL1 over-expression in T-ALL their levels should be decreased in primary leukemia cells as compared to normal developing T-cells. In agreement, we found that
miR-101 and miR-140-5p were less expressed in T-ALL patient samples than in more differentiated thymocytes (Figure 6B). This is in accordance with the fact that TAL1 mRNA is not detected beyond the early thymic progenitor

\section{A}

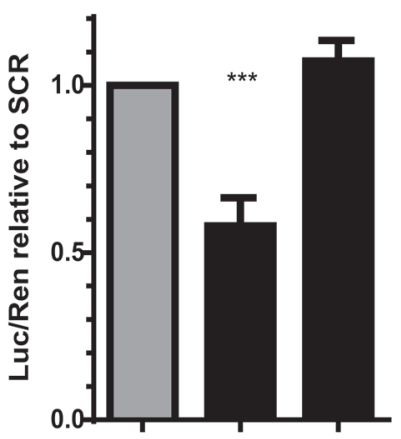

TAL13'UTR WT WT 101 mut

MIRNA SCR $101 \quad 101$

B

C
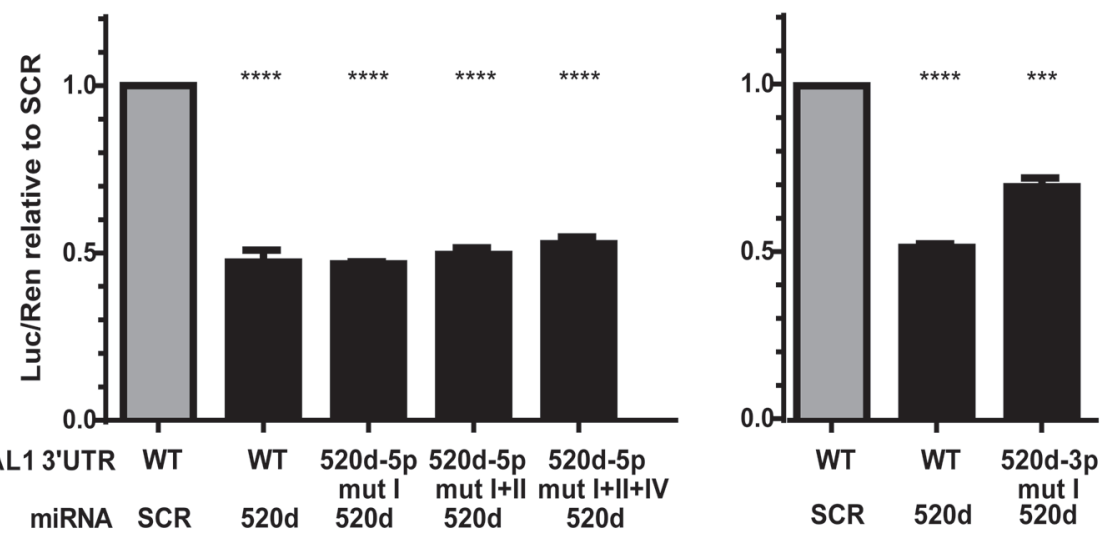

D

$\mathbf{E}$
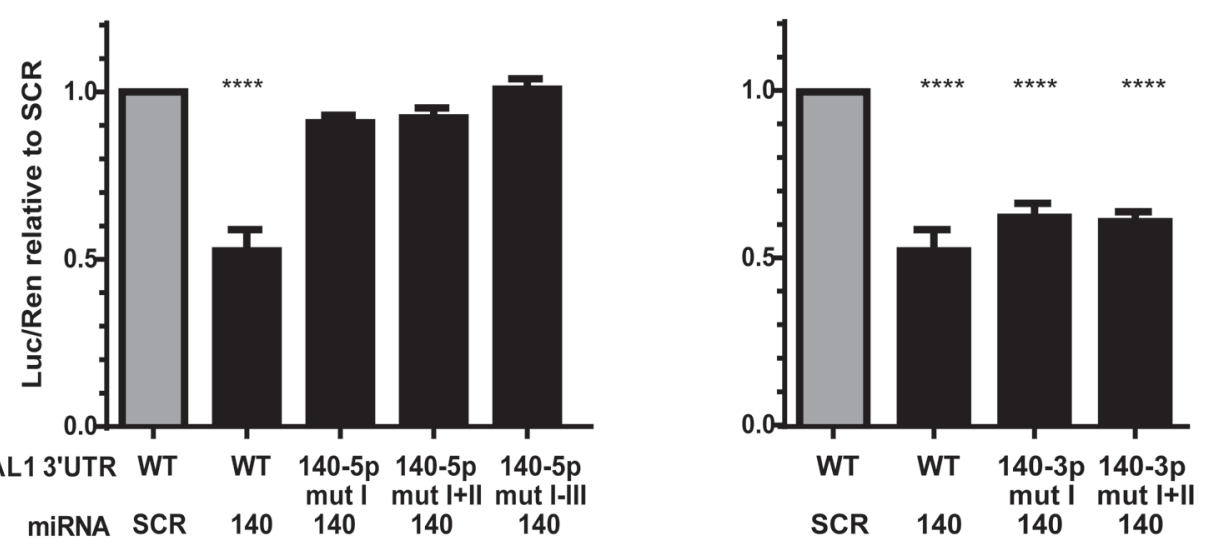

Figure 3: Effect of mutagenesis on microRNA-mediated repression of TAL1 3'UTR. Luciferase activity of wild-type (WT) or mutant (mut) TAL1 3'UTRs in the presence of the corresponding miRNAs. Results were normalized to scramble (SCR) miRNA on WT TAL1 3'UTR: A. miR-101, B, C. miR-520d, and D, E. miR-140. The mutations were made in a cumulative manner, i.e. mut II was performed on the 3'UTR bearing already mut I and so on. The graphs represent 4 independent experiments with two replicates. Statistical analysis was performed by One-way ANOVA using the WT SCR condition as control condition. $(* * * p<0.001 ; * * * * p<0.0001)$. 
stage [4]. Moreover, T-ALL patient samples expressed lower levels of miR-101, miR-140-5p, miR-448 and miR-485-5p as compared to normal bone marrow cells (Figure 6C), which still express TAL1 (data not shown). These data provide support to the notion that the identified miRNAs may act as physiological upstream negative regulators of TAL1 that are aberrantly down-regulated in T-ALL, thereby contributing to TAL1 overexpression.

\section{DISCUSSION}

While it is now known that TAL1 regulates the expression of numerous miRNA genes [27, 28], several observations led us to hypothesize that upstream miRNA networks could be involved in potentiating TAL1 overexpression in T-ALL. First, more than $60 \%$ of T-ALL patients display aberrantly high levels of TAL1
A

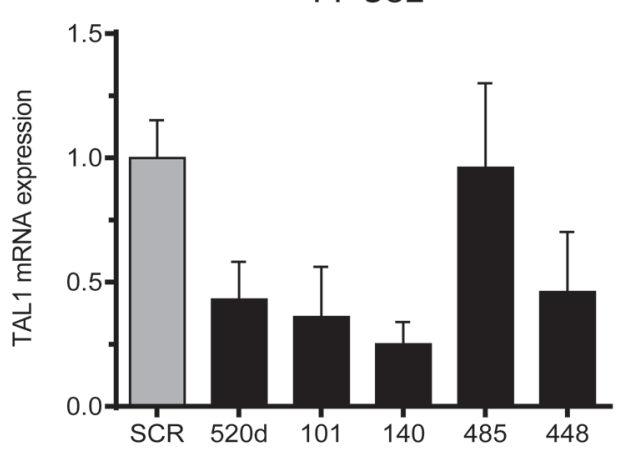

SUP-T1

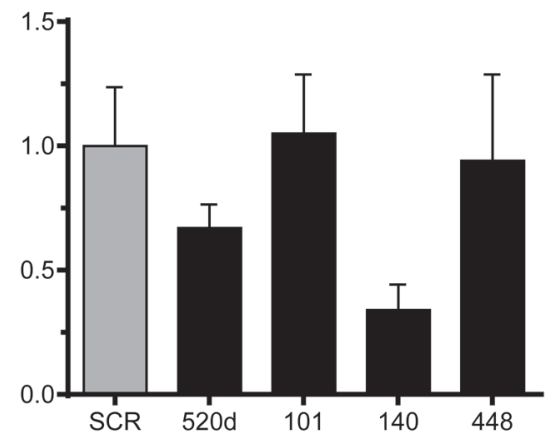

B
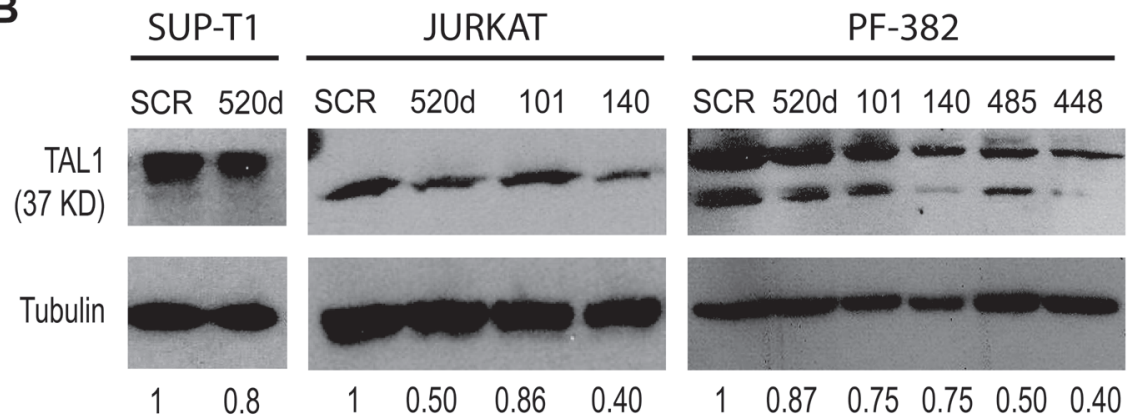

C

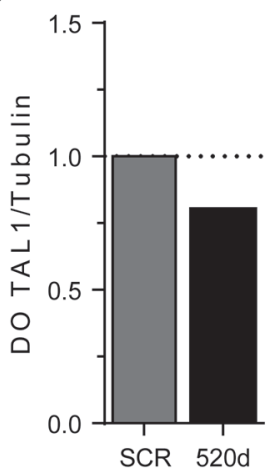

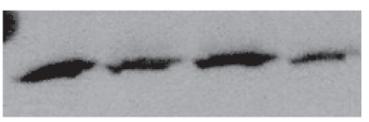
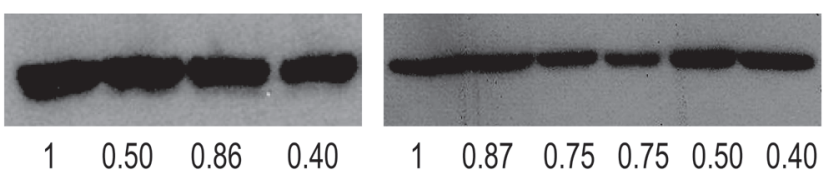

$\begin{array}{llllll}1 & 0.87 & 0.75 & 0.75 & 0.50 & 0.40\end{array}$
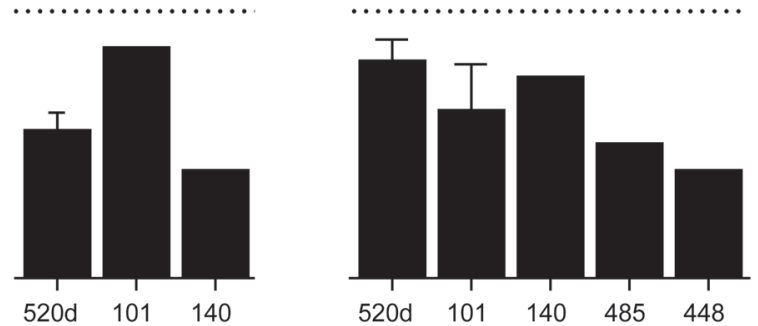

Figure 4: Ectopic expression of miR-520d, -101, -140, -485 and -448 down-regulates endogenous TAL1 mRNA and protein levels in T-ALL cell lines. A. TAL1 transcript levels were analyzed by qPCR upon transfection of PF-382 and SUP-T1 cells with miR-Vec vectors. Values indicate the mean \pm lower and upper limit of 3 technical replicates relatively to the scramble (SCR) transfection. B. TAL1 protein levels were evaluated by western blot analysis in T-ALL cell lines upon transfection with miR-Vec vectors. The relative TAL1 protein levels in T-ALL cell lines were normalized using $\alpha$-Tubulin as loading control. C. Densitometric values (DO) of TAL1 levels (ratio to loading control) normalized to those measured in the presence of the respective scramble vector. 
transcript but only roughly half display chromosomal translocations or DNA rearrangements known to activate TAL1 transcription [5]. Second, TAL1 is a putative target of several miRNAs that are up-regulated in hematopoietic stem cells, such as hsa-miR-17-5p, hsa-miR-197, hsamiR-106 and hsa-miR-20 [39], and of some that are down-regulated in differentiated megakaryocytes, such as hsa-miR-106 and hsa-miR-20 [40], suggesting that miRNAs might regulate TAL1 at different stages of hematopoietic development. Finally, the LIM only protein LMO2, a TAL1 co-factor, was shown to be regulated by a microRNA, miR-223, namely during erythroid differentiation [41]. The majority of T-ALL patients with LMO ectopic expression also overexpress TAL1 [6] and both transcription factors cooperate to induce leukemia in transgenic mice [42]. These facts contributed to our speculation that, similar to LMO2, TAL1 could be regulated by miRNAs during normal hematopoiesis, in such way that TAL1 levels decrease during normal T-cell development at least in part due to miRNA-dependent down-regulation. In this case, TAL1 over-expression in some T-ALL cases could result from down-regulation of critical miRNA genes in the context of the disease. In other words, these miRNAs would have a tumor suppressor-like role by keeping in check TAL1. Interestingly, miR-101 [20, 43-52], miR-140-5p [53-56], miR-520-5p [57], and miR-485-5p [58-60], are all reported as putative tumor suppressors in different cancers.

The tumor suppressive function of miR-101 in inhibiting cell proliferation, migration, invasion and tumor growth, has been demonstrated in prostate [43], bladder [44], gastric [45, 48], and renal cell [49] carcinoma, pancreatic ductal adenocarcinoma [50] and melanoma [52], mainly due to targeting of the histone methyltransferase EZH2. In the context of hematopoietic malignancies, miR-101 was found down-regulated in samples of Burkitt lymphoma [46] and pediatric B-ALL patients [20,51]. Adult T-cell leukemia/lymphoma patient cells have increased expression of EZH2 that is inversely correlated with the expression of miR-101 [47]. However, deleterious mutations in EZH2 have been found in T-ALL patients (mainly associated with immature and not more
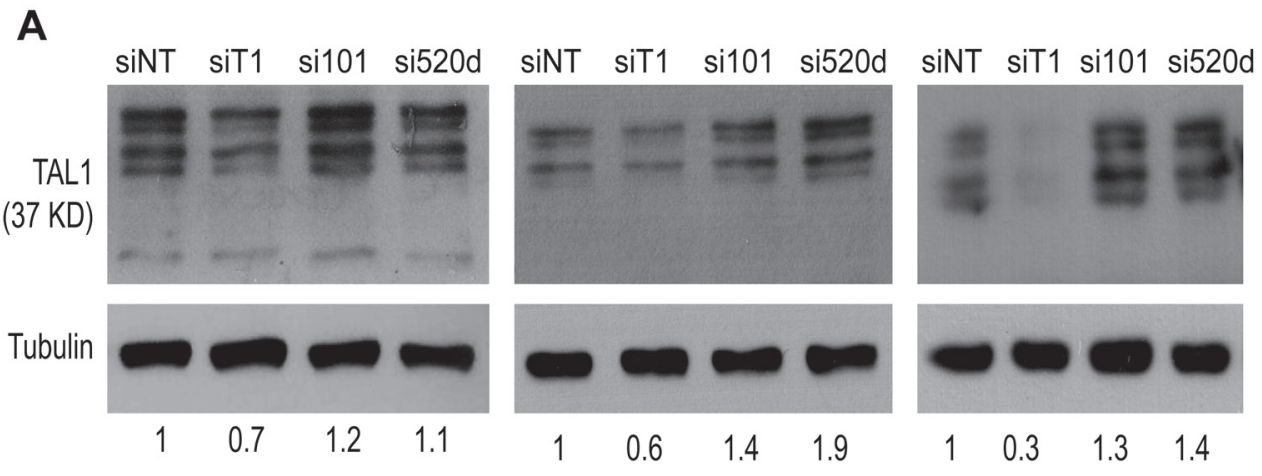

B

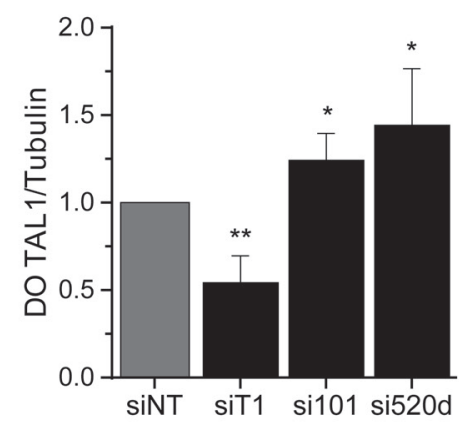

C

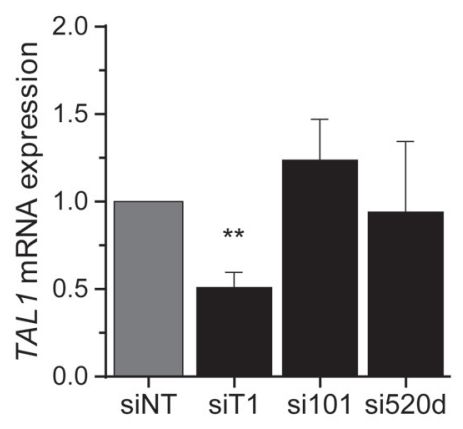

Figure 5: Inhibition of miR-520d-5p and miR-101 increases endogenous TAL1 protein levels in T-ALL cells. A. Western blot and densitometric and analysis of TAL1 expression in CCRF-CEM cells upon nucleofection with microRNA inhibitors (si101 against hsa-miR-101 or si520d against hsa-miR-520d-5p), a siRNA against TAL1 (siT1) or a non-targeting siRNA control (siNT). $\alpha$-Tubulin was used as loading control. Here are represented three independent nucleofection experiments. The numeric values depicted bellow represent the densitometric values normalized to the TAL1 expression in the siNT control for each experiment. B. Densitometric values (DO) of TAL1 expression of four independent nucleofection experiments were normalized to the $\alpha$-Tubulin expression and compared to the control. C. TAL1 transcript levels analysis by qPCR of the same three independent nucleofection experiments depicted in (A) (B, C) Values indicate the mean \pm standard deviation relatively to the scramble nucleofection of independent nucleofection experiments and were analyzed using a Student's t-test $(* \mathrm{p}<0.05 ; * * \mathrm{p}<0.01)$. 
differentiated cases), suggestive of a tumor suppressor role in T-cells. In our work, we showed that TAL1 is a direct target of miR-101 in T-ALL cell lines, in accordance with studies indicating a possible tumor suppressor role of miR101 has in hematological malignancies. Given that our previous findings about TAL1-transcriptionally regulated miRNA expression [27] did not recognize miR-101 as a possible transcriptional TAL1 target, the low expression of the miRNA found in primary T-ALL samples and cell lines foresees a tumor-suppressive role for miR-101 in T-cell transformation, which might be in part mediated through down-regulation of TAL1 rather than EZH2. The miR-140-5p has also been associated with suppression of tumorigenesis in osteosarcoma and in colon [53], breast
[54], lung [56] and hepatocellular [55] carcinoma. So far, the direct validated targets of this miRNA include stem cell self-renewal regulator SOX2 in breast cancer [54], TGFBR1 and FGF9 in hepatocellular carcinoma [55], SOX9 and ALDH1 in ductal carcinoma in situ [61] and IGF1R in lung cancer [56]. In addition, predicted targets for miR-101 besides TAL1 include MCL1 and RUNX1, being the latest a downstream TAL1 target and part of the TAL1+ gene signature described for T-ALL patients. $V E G F$ and HDAC4 are miR-140-5p predicted targets. Whether and how regulation of any of these genes by miR101 and miR-140-5p is biologically relevant for thymocyte development and leukemogenesis, and may complement effects on TAL1, has not been addressed so far.
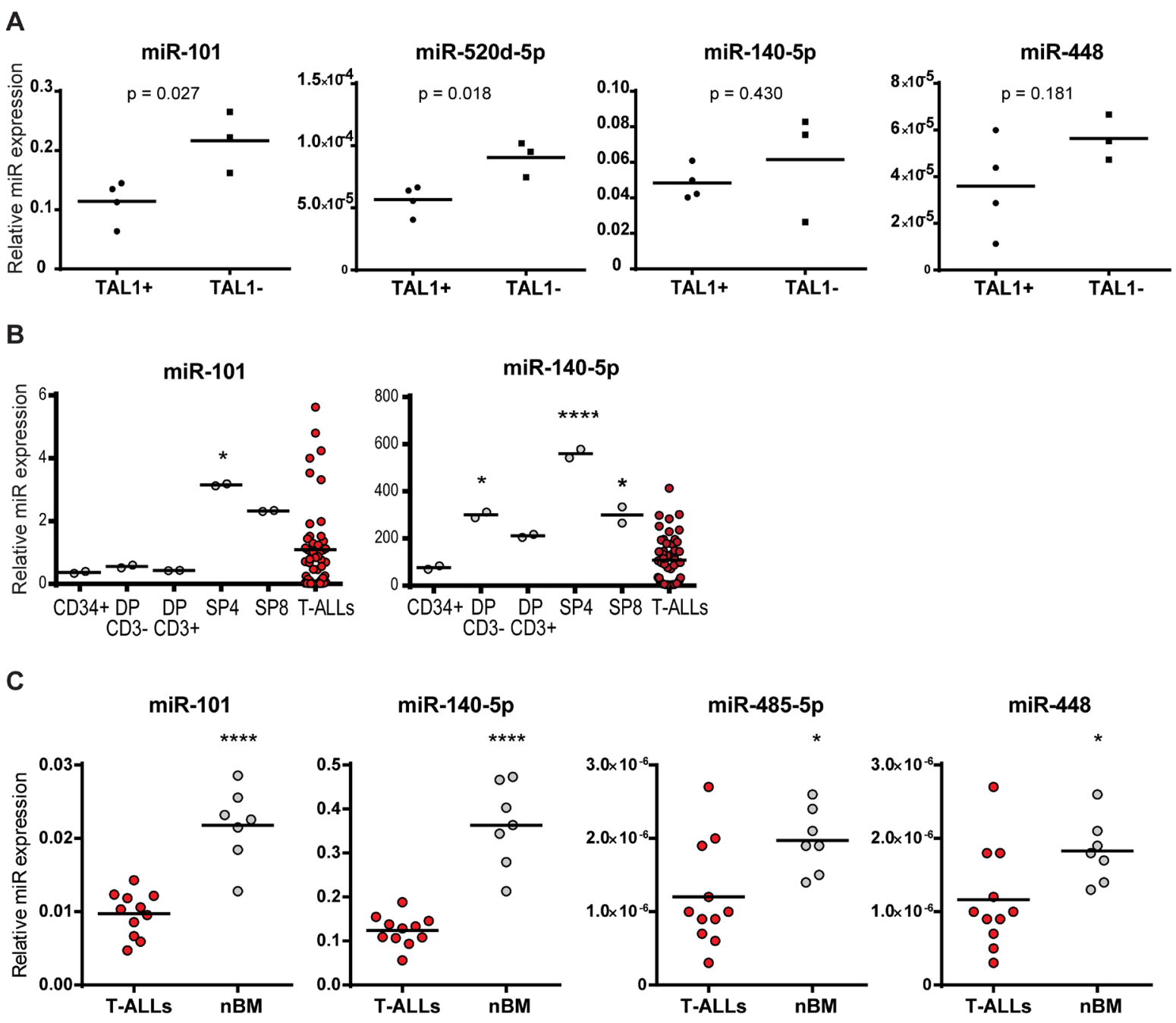

Figure 6: MicroRNA expression in T-ALL cell lines, patients and normal counterparts. A. Expression of miR-101, miR520d-5p, miR-140-5p and miR-448 was determined by qRT-PCR and normalized to SNORD38B expression in TAL1-positive (SUP-T1, CCRF-CEM, TAIL7, PF-382) and TAL1-negative (HPB-ALL, P12-ICHIKAWA, TALL-1) T-ALL human cell lines. Groups were compared using a 2-tailed Student's t-test. B, C. Expression of indicated miRNAs was analyzed using publicly available datasets. (B) MiRNA expression in T-ALL patients was compared to normal thymic populations (DP - double positive; SP4 - single positive CD4; SP8 - single positive CD8 T-cells). Data collected from [23]. (C) MiRNA expression in T-ALL patients was compared to normal bone marrow samples (nBM). Data collected from [20]. Statistical analysis was performed by One-way ANOVA $(* \mathrm{p}<0.05 ; * * * * \mathrm{p}<0.0001)$. 
Given the relatively mild effects of each miRNA on TAL1 protein expression, which are in accordance to what is described for microRNA post-transcriptional regulation $[37,38]$, we do not foresee that their deregulated expression can fully justify the high levels of TAL1 ectopic expression observed in T-ALL patients, unless it occurred in a coordinated fashion involving several TAL1targeting miRNA genes as a consequence of a putative common upstream event. On the other hand, the fact that miR-140-5p is up-regulated in the different thymocyte subpopulations as compared to CD34+ cells may suggest that miR-140-5p could be part of the regulatory network that prevents TAL1 expression in normal committed thymic progenitors. In fact, the microRNA genes we identified, and others that remain to be, may partake in preventing TAL1 expression at different stages of T-cell development. For instance, miR-101 may be involved in TAL1 inhibition especially within SP thymocytes (where it is most highly expressed). In this way, different sets of microRNA genes could be involved, probably in coordination with other epigenetic mechanisms, in the continued silencing of TAL1 throughout normal T-cell development.

Also of potential relevance to the regulation of TAL1 by microRNAs in the context of T-ALL is the knowledge that mRNA transcripts in cancer cells frequently display shorter 3'UTRs then those in normal cells [62]. Putative poly-adenylation sites are present in the 3427 nt-long TAL1 3'UTR: two close AAUAAA poly-adenylation sites at positions 3052 and 3413 and one alternative AAGAAA poly-adenylation site at 1300 , raising the possibility that shorter transcripts could exist in T-ALL cells that would exclude the MRE of some of the targeting miRNAs, consequently rendering TAL1 more 'resistant' to miR-mediated downregulation and thereby promoting TAL1 overexpression. While we have not explored this possibility in the current manuscript, we note that even if such transcripts prevail in T-ALL cases, the most upstream canonical poly-adenylation site would only protect the MRE corresponding to miR-520-3p, miR-140-3p (both of which we showed to have no effect on reporter expression recovery upon mutagenesis assays) and the 4th MRE for miR-520-5p, which we showed that, together other two MREs for miR-520-5p, is not sufficient to recover the reporter expression. In other words, the canonical poly-A sites are not predicted to protect TAL1 mRNA from the microRNAs analyzed in this study.

Given the evidence we presented for TAL1 posttranscriptional regulation by microRNAs we speculate that TAL1 ectopic expression in T-ALL may, in some cases, be amplified by abnormal down-regulation of miRNAs targeting TAL1. This hypothesis implicates, once again, that miRNAs are physiologically involved in TAL1 regulation during normal development. Upon commitment to specific hematopoietic lineages the regulation of TAL1 expression involves enhancer/promoter interactions, epigenetic alterations and trans-acting mechanisms, resulting in TAL1 silencing in the lymphoid lineage. A possibility is that modest mRNA destabilization perpetuated by the miRNAs quickly yields substantial repression of protein output after transcription of the mRNA ceases. A similar mode of action has been described for other miRNAs in other physiological conditions [63]. In this model, depending on the threshold level for protein function, the mRNA decay rate, and the protein decay rate, modest miRNA-mediated repression can lead to substantially reduced protein and a much more rapid transition to the off state. If the miRNA also mediates translational repression, the transition to the off state is further accelerated [63]. If we consider that in a pre-leukemic stage the normal mechanisms that lead to TAL1 transcriptional silencing are significantly decreased or disrupted, a concomitant down-regulation of miRNA-TAL1 interactions could have a considerable positive impact on TAL1 protein levels and consequently on progression to overt leukemia. Evidently, a critical question that warrants investigation relates to the upstream mechanisms that lead to decreased expression of TAL1-regulating microRNAs in T-ALL.

\section{MATERIALS AND METHODS}

\section{MicroRNA nomenclature and annotation}

Official nomenclature and sequence annotation for the relevant microRNAs is based on the miRBase version 21 (2014) [64]. We listed the microRNA sequences relevant for this study in Supplementary Table 3. Regarding the miRNAs of interest, the only nomenclature difference from the miR-Vec library [33] refers to miR101 , which is currently named miR-101-3p according to miRBase version 21 [65]. The original nomenclature of the miR-Vec library vectors was kept [33].

\section{RNA extraction, RT-PCR and quantitative-PCR}

RNA was extracted using TRIZOL (Life Technologies Corporation) according to the manufacturer's instructions. Amounts ranging from 1001000 ng of total RNA were reverse transcribed using miRCURY LNA ${ }^{\mathrm{TM}}$ Universal RT kit (Exiqon). Real time PCR was performed with commercially available LNAbased primers (Exiqon) for mature microRNA detection with SYBRGreen (Exiqon) in a ViiA7 Real-Time PCR System (Life Technologies). Relative expression of the microRNAs was normalized to $S N O R D 38 B$ expression using the ddCt method.

\section{Computational prediction of TAL1 3'UTR targeting by microRNAs}

PicTar (4-way) [66], TargetScanS release 4.2 [67], miRBase [64], microRNA.org [68-70], DIANAmicroT algorithm V3.0 [71], miRDB [72] and StarBase [73] 
web-based bioinformatics tools were used, at the beginning of the study, to perform the identification of putative regulators of TAL1 and compiling the list of miRNAs that potentially regulate TAL1 transcript.

\section{Luciferase activity assays}

A commercially available reporter plasmid coding for firefly and renilla luciferases and with TAL1 3'UTR (GeneCopoeia Inc) downstream of the luciferase open reading frame (pLuc-TAL1-3'UTR) was used. The miRVec vectors $[32,33]$, express the stem loop sequence (pre-miR) and were co-transfected into 293T cells. All the vectors used in this study were sequenced and the pre-miR sequences verified. All the miRNAs tested are listed in Supplementary Table 2. Briefly, 1.5x10 $293 \mathrm{~T}$ cells were cultured for $24 \mathrm{~h}$, and transfected with a mixture of $2 \mu \mathrm{l}$ Lipofectamine 2000 (Life Technologies), 200 $\mu 1$ of OPTIMEM medium (GIBCO), 100ng of the reporter vector and 500ng of the miRNA-expressing vector. After 24h, cells were lysed and processed according to the Dual-Luciferase Reporter Assay System (Promega). The firefly luciferase and renilla luciferase activity was measured in an Infinite M200 plate reader (Tecan). For the firefly activity calculations, the values were normalized to renilla luminescence and the average of the two technical replicates was calculated. The values of at least three independent transfection experiments were normalized to the measurements of the corresponding scramble transfection.

\section{Site directed mutagenesis}

To point-mutate the TAL1 3'UTR in the pLucTAL1-3'UTR vector, a PCR-based commercial kit was used according to the manufacturer instructions QuikChange II XL site-directed mutagenesis (Agilent). All mutations were confirmed by sanger-sequencing. When more than one miRNA target site was possible for a given miRNA, the mutations were sequentially performed and named from the most upstream to the most downstream. The primers used in the site-directed mutagenesis are depicted in Supplementary Table 4.

\section{Cell lines}

The human T-ALL cell lines were maintained in RPMI medium (GIBCO) supplemented with 10\% FBS and split every 2-3 days. 293T cells were maintained in DMEM medium (GIBCO) supplemented with 10\% FBS and split every 2 days. Cells were cultured at $37^{\circ} \mathrm{C}$ with $5 \% \mathrm{CO} 2$. At the indicated time points, the cells were harvested and processed as indicated for RNA and protein extraction.

\section{Electroporation of miR-Vec vectors in T-ALL cell lines}

Cell lines were transiently transfected with the corresponding miR-Vec vectors or scramble control (miR-Vec-SCR). To circumvent the difficulty imposed by low efficiency of transfection on the T-ALL cell lines, we co-transfected each miR-Vec with a GFP expressing vector (pMax, Lonza) and cells were sorted to enrich for high GFP+ populations. A total of $30 \mu \mathrm{g}$ of DNA $(9 \mu \mathrm{g}$ of pMax and $21 \mu \mathrm{g}$ of miR-Vec) were added to $10^{7} \mathrm{~T}-\mathrm{ALL}$ cells in the appropriate volume of pre-warmed RPMI-10 medium (without antibiotics). Electroporation was performed using Gene Pulser II in $4 \mathrm{~cm}$-gap cuvettes (Bio-Rad), with the parameters depicted in Supplementary Table 5. After 24h, cells were sorted to obtain the GFP-expressing cells using a FACSAria III (BD Biosciences) and were collected for RNA and/or protein extraction $48 \mathrm{~h}$ later.

\section{Nucleofection of T-ALL cells}

Nucleofection of CCRF-CEM was performed using the Amaxa Nucleofector II (Lonza) with the X-001 program, according to the manufacturer's instructions. For miR-101 or miR-520d-5p knockdown, $2 \mu \mathrm{M}$ of miRCURY LNA $^{\mathrm{TM}}$ microRNA Inhibitors (Exiqon) and non-targeting control were used. After nucleofection, the cells were cultured for $48 \mathrm{~h}$ in RPMI-10 medium.

\section{Immunoblot}

Cell lysates were prepared as described [74] using the following antibodies: $\alpha$-Tubulin (Sigma, Clone DM 1A) and TAL1 (Millipore, clone BTL73). Densitometry analysis was performed using Adobe Photoshop CS5 Extended software. Each band was analyzed with a constant frame and normalized to the respective loading control. Densitometry values are expressed in arbitrary units.

\section{Statistical analysis}

Statistical differences between mean values were evaluated using 2-tailed Student's t-test or One-way ANOVA, as appropriate. Significance was set for $\mathrm{P}<0.05$. All analyses were performed using GraphPad Prism 6.0 (GraphPad Software).

\section{ACKNOWLEDGMENTS}

These studies were financed by Liga Portuguesa Contra o Cancro (Terry Fox Award) and by Fundação para a Ciência e a Tecnologia (project PTDC/BIMONC/1548/2012). NCC received an FCT-SFRH PhD 
fellowship. JTB is supported by an FCT Consolidation Grant. The Cell Division and Cancer group of the CNIO is funded by the Spanish Ministry of Economy and Competitiveness (MINECO; SAF2012-38215; Consolider-Ingenio 2010 Programme SAF2014-57791REDC; Red Temática CellSYS BFU2014-52125-REDT), and the Comunidad de Madrid (OncoCycle Programme; S2010/BMD-2470).

\section{CONFLICTS OF INTEREST}

The authors declare no conflicts of interest.

\section{REFERENCES}

1. Shivdasani RA, Mayer EL, Orkin SH. Absence of blood formation in mice lacking the T-cell leukaemia oncoprotein tal-1/SCL. Nature. 1995; 373:432-434.

2. Porcher C, Swat W, Rockwell K, Fujiwara Y, Alt FW, Orkin SH. The T cell leukemia oncoprotein SCL/tal-1 is essential for development of all hematopoietic lineages. Cell. 1996; 86:47-57.

3. Brunet de la Grange P, Armstrong F, Duval V, Rouyez MC, Goardon N, Romeo PH, Pflumio F. Low SCL/TAL1 expression reveals its major role in adult hematopoietic myeloid progenitors and stem cells. Blood. 2006; 108:2998-3004.

4. Zhang Y, Payne KJ, Zhu Y, Price MA, Parrish YK, Zielinska E, Barsky LW, Crooks GM. SCL expression at critical points in human hematopoietic lineage commitment. Stem Cells. 2005; 23:852-860.

5. Bash ROHSTCFCWMAMSRGBR. Does activation of the TAL1 gene occur in a majority of patients with T-cell acute lymphoblastic leukemia? A pediatric oncology group study. Blood. 1995; 86:666-676.

6. Ferrando AA, Neuberg DS, Staunton J, Loh ML, Huard C, Raimondi SC, Behm FG, Pui C-H, Downing JR, Gilliland DG, Lander ES, Golub TR, Look AT. Gene expression signatures define novel oncogenic pathways in T cell acute lymphoblastic leukemia. Cancer Cell. 2002; 1:75-87.

7. Ferrando AAHSPTHMHTFEALAT. Biallelic transcriptional activation of oncogenic transcription factors in T-cell acute lymphoblastic leukemia. Blood. 2003; 103:1909-1911.

8. Aplan PD, Lombardi DP, Reaman GH, Sather HN, Hammond GD, Kirsch IR. Involvement of the putative hematopoietic transcription factor SCL in T-cell acute lymphoblastic leukemia. Blood. 1992; 79:1327-1333.

9. Zhou Y, Kurukuti S, Saffrey P, Vukovic M, Michie AM, Strogantsev R, West AG, Vetrie D. Chromatin looping defines expression of TAL1, its flanking genes, and regulation in T-ALL. Blood. 2013; 122:4199-4209.

10. Patel B, Kang Y, Cui K, Litt M, Riberio MS, Deng C, Salz T, Casada S, Fu X, Qiu Y, Zhao K, Huang S. Aberrant TAL1 activation is mediated by an interchromosomal interaction in human T-cell acute lymphoblastic leukemia. Leukemia. 2014; 28:349-361.

11. Mansour MR, Abraham BJ, Anders L, Berezovskaya A, Gutierrez A, Durbin AD, Etchin J, Lawton L, Sallan SE, Silverman LB, Loh ML, Hunger SP, Sanda T, Young RA, Look AT. Oncogene regulation. An oncogenic superenhancer formed through somatic mutation of a noncoding intergenic element. Science. 2014; 346:1373-1377.

12. Navarro JM, Touzart A, Pradel LC, Loosveld M, Koubi M, Fenouil R, Le Noir S, Maqbool MA, Morgado E, Gregoire C, Jaeger S, Mamessier E, Pignon C, Hacein-Bey-Abina S, Malissen B, Gut M, et al. Site- and allele-specific polycomb dysregulation in T-cell leukaemia. Nature communications. 2015; 6:6094.

13. Orom UA, Derrien T, Beringer M, Gumireddy K, Gardini A, Bussotti G, Lai F, Zytnicki M, Notredame C, Huang Q, Guigo R, Shiekhattar R. Long noncoding RNAs with enhancer-like function in human cells. Cell. 2010; 143:46-58.

14. Lee RC, Feinbaum RL, Ambros V. The C. elegans heterochronic gene lin-4 encodes small RNAs with antisense complementarity to lin-14. Cell. 1993; 75:843-854.

15. Lagos-Quintana M, Rauhut R, Lendeckel W, Tuschl T. Identification of Novel Genes Coding for Small Expressed RNAs. Science. 2001; 294:853-858.

16. Lau NC, Lim LP, Weinstein EG, Bartel DP. An Abundant Class of Tiny RNAs with Probable Regulatory Roles in Caenorhabditis elegans. Science. 2001; 294:858-862.

17. Lim LP, Lau NC, Garrett-Engele P, Grimson A, Schelter JM, Castle J, Bartel DP, Linsley PS, Johnson JM. Microarray analysis shows that some microRNAs downregulate large numbers of target mRNAs. Nature. 2005; 433:769-773.

18. Lu J, Getz G, Miska EA, Alvarez-Saavedra E, Lamb J, Peck D, Sweet-Cordero A, Ebert BL, Mak RH, Ferrando AA, Downing JR, Jacks T, Horvitz HR, Golub TR. MicroRNA expression profiles classify human cancers. Nature. 2005; 435:834-838.

19. Fabbri M, Croce CM, Calin GA. MicroRNAs in the ontogeny of leukemias and lymphomas. Leukemia \& Lymphoma. 2009; 50:160-170.

20. Schotte D, De Menezes RX, Akbari Moqadam F, Mohammadi Khankahdani L, Lange-Turenhout E, Chen C, Pieters R, Den Boer ML. MicroRNAs characterize genetic diversity and drug resistance in pediatric acute lymphoblastic leukemia. Haematologica. 2011.

21. de Oliveira JC, Scrideli CA, Brassesco MS, Morales AG, Pezuk JA, Queiroz RdP, Yunes JA, Brandalise SR, Tone LG. Differential MiRNA expression in childhood acute lymphoblastic leukemia and association with clinical and biological features. Leukemia Research. 2012; 36:293-298.

22. Mavrakis KJ, Wolfe AL, Oricchio E, Palomero T, de Keersmaecker K, McJunkin K, Zuber J, James T, Khan AA, Leslie CS, Parker JS, Paddison PJ, Tam W, Ferrando 
A, Wendel H-G. Genome-wide RNA-mediated interference screen identifies miR-19 targets in Notch-induced T-cell acute lymphoblastic leukaemia. Nat Cell Biol. 2010; 12:372-379.

23. Mavrakis KJ, Van Der Meulen J, Wolfe AL, Liu X, Mets E, Taghon T, Khan AA, Setty M, Rondou P, Vandenberghe P, Delabesse E, Benoit Y, Socci NB, Leslie CS, Van Vlierberghe P, Speleman F, et al. A cooperative microRNAtumor suppressor gene network in acute T-cell lymphoblastic leukemia (T-ALL). Nat Genet. 2011; 43:673-678.

24. Lv M, Zhang X, Jia H, Li D, Zhang B, Zhang H, Hong M, Jiang T, Jiang Q, Lu J, Huang X, Huang B. An oncogenic role of miR-142-3p in human T-cell acute lymphoblastic leukemia (T-ALL) by targeting glucocorticoid receptor[alpha] and cAMP/PKA pathways. Leukemia. 2012; 26:769-777.

25. Kumar V, Palermo R, Talora C, Campese AF, Checquolo S, Bellavia D, Tottone L, Testa G, Miele E, Indraccolo S, Amadori A, Ferretti E, Gulino A, Vacca A, Screpanti I. Notch and NF-kB signaling pathways regulate miR223/FBXW7 axis in T-cell acute lymphoblastic leukemia. Leukemia. 2014; 28:2324-2335.

26. Sanghvi VR, Mavrakis KJ, Van der Meulen J, Boice M, Wolfe AL, Carty M, Mohan P, Rondou P, Socci ND, Benoit Y, Taghon T, Van Vlierberghe P, Leslie CS, Speleman F, Wendel HG. Characterization of a set of tumor suppressor microRNAs in $\mathrm{T}$ cell acute lymphoblastic leukemia. Science signaling. 2014; 7:ra111.

27. Correia NC, Durinck K, Leite AP, Ongenaert M, Rondou P, Speleman F, Enguita FJ, Barata JT. Novel TAL1 targets beyond protein-coding genes: identification of TAL1regulated microRNAs in T-cell acute lymphoblastic leukemia. Leukemia. 2013; 27:1603-1606.

28. Mansour MR, Sanda T, Lawton LN, Li X, Kreslavsky T, Novina CD, Brand M, Gutierrez A, Kelliher MA, Jamieson $\mathrm{CH}$, von Boehmer H, Young RA, Look AT. The TAL1 complex targets the FBXW7 tumor suppressor by activating miR-223 in human T cell acute lymphoblastic leukemia. J Exp Med. 2013; 210:1545-1557.

29. Li X, Sanda T, Look AT, Novina CD, von Boehmer H. Repression of tumor suppressor miR-451 is essential for NOTCH1-induced oncogenesis in T-ALL. The Journal of Experimental Medicine. 2011; 208:663-675.

30. Fragoso R, Mao T, Wang S, Schaffert S, Gong X, Yue S, Luong R, Min H, Yashiro-Ohtani Y, Davis M, Pear W, Chen CZ. Modulating the strength and threshold of NOTCH oncogenic signals by mir-181a-1/b-1. PLoS Genet. 2012; 8:e1002855.

31. Hammell M, Long D, Zhang L, Lee A, Carmack CS, Han M, Ding Y, Ambros V. mirWIP: microRNA target prediction based on microRNA-containing ribonucleoproteinenriched transcripts. Nat Methods. 2008; 5:813-819.

32. Bueno MJ, Gomez de Cedron M, Laresgoiti U, FernandezPiqueras J, Zubiaga AM, Malumbres M. Multiple
E2F-induced microRNAs prevent replicative stress in response to mitogenic signaling. Molecular and cellular biology. 2010; 30:2983-2995.

33. Voorhoeve PM, le Sage C, Schrier M, Gillis AJ, Stoop H, Nagel R, Liu YP, van Duijse J, Drost J, Griekspoor A, Zlotorynski E, Yabuta N, De Vita G, Nojima H, Looijenga LH, Agami R. A genetic screen implicates miRNA-372 and miRNA-373 as oncogenes in testicular germ cell tumors. Cell. 2006; 124:1169-1181.

34. Xiao C, Srinivasan L, Calado DP, Patterson HC, Zhang B, Wang J, Henderson JM, Kutok JL, Rajewsky K. Lymphoproliferative disease and autoimmunity in mice with increased miR-17-92 expression in lymphocytes. Nat Immunol. 2008; 9:405-414.

35. He L, Thomson JM, Hemann MT, Hernando-Monge E, Mu D, Goodson S, Powers S, Cordon-Cardo C, Lowe SW, Hannon GJ, Hammond SM. A microRNA polycistron as a potential human oncogene. Nature. 2005; 435:828-833.

36. O'Donnell KA, Wentzel EA, Zeller KI, Dang CV, Mendell JT. c-Myc-regulated microRNAs modulate E2F1 expression. Nature. 2005; 435:839-843.

37. Baek D, Villén J, Shin C, Camargo FD, Gygi SP, Bartel DP. The impact of microRNAs on protein output. Nature. 2008; 455:64-71.

38. Selbach M, Schwanhausser B, Thierfelder N, Fang Z, Khanin R, Rajewsky N. Widespread changes in protein synthesis induced by microRNAs. Nature. 2008; 455:58-63.

39. Choong ML, Yang HH, McNiece I. MicroRNA expression profiling during human cord blood-derived CD34 cell erythropoiesis. Exp Hematol. 2007; 35:551-564.

40. Garzon R, Pichiorri F, Palumbo T, Iuliano R, Cimmino A, Aqeilan R, Volinia S, Bhatt D, Alder H, Marcucci G, Calin GA, Liu CG, Bloomfield CD, Andreeff M, Croce CM. MicroRNA fingerprints during human megakaryocytopoiesis. Proc Natl Acad Sci U S A. 2006; 103:5078-5083.

41. Felli N, Pedini F, Romania P, Biffoni M, Morsilli O, Castelli G, Santoro S, Chicarella S, Sorrentino A, Peschle C, Marziali G. MicroRNA 223-dependent expression of LMO2 regulates normal erythropoiesis. Haematologica. 2009; 94:479-486.

42. Larson RC, Lavenir I, Larson TA, Baer R, Warren AJ, Wadman I, Nottage K, Rabbitts TH. Protein dimerization between Lmo2 (Rbtn2) and Tal1 alters thymocyte development and potentiates $\mathrm{T}$ cell tumorigenesis in transgenic mice. The EMBO journal. 1996; 15:1021-1027.

43. Varambally S, Cao Q, Mani RS, Shankar S, Wang X, Ateeq B, Laxman B, Cao X, Jing X, Ramnarayanan K, Brenner JC, Yu J, Kim JH, Han B, Tan P, Kumar-Sinha C, et al. Genomic loss of microRNA-101 leads to overexpression of histone methyltransferase EZH2 in cancer. Science. 2008; 322:1695-1699.

44. Friedman JM, Liang G, Liu CC, Wolff EM, Tsai YC, Ye W, Zhou X, Jones PA. The putative tumor suppressor microRNA-101 modulates the cancer epigenome by 
repressing the polycomb group protein EZH2. Cancer Res. 2009; 69:2623-2629.

45. Wang HJ, Ruan HJ, He XJ, Ma YY, Jiang XT, Xia YJ, Ye ZY, Tao HQ. MicroRNA-101 is down-regulated in gastric cancer and involved in cell migration and invasion. Eur $\mathrm{J}$ Cancer. 2010; 46:2295-2303.

46. Robertus JL, Kluiver J, Weggemans C, Harms G, Reijmers RM, Swart Y, Kok K, Rosati S, Schuuring E, van Imhoff G, Pals ST, Kluin P, van den Berg A. MiRNA profiling in B non-Hodgkin lymphoma: a MYC-related miRNA profile characterizes Burkitt lymphoma. Br J Haematol. 2010; 149:896-899.

47. Sasaki D, Imaizumi Y, Hasegawa H, Osaka A, Tsukasaki K, Choi YL, Mano H, Marquez VE, Hayashi T, Yanagihara K, Moriwaki Y, Miyazaki Y, Kamihira S, Yamada Y. Overexpression of Enhancer of zeste homolog 2 with trimethylation of lysine 27 on histone H3 in adult T-cell leukemia/lymphoma as a target for epigenetic therapy. Haematologica. 2011; 96:712-719.

48. Carvalho J, van Grieken NC, Pereira PM, Sousa S, Tijssen M, Buffart TE, Diosdado B, Grabsch H, Santos MA, Meijer G, Seruca R, Carvalho B, Oliveira C. Lack of microRNA-101 causes E-cadherin functional deregulation through EZH2 up-regulation in intestinal gastric cancer. J Pathol. 2012; 228:31-44.

49. Sakurai T, Bilim VN, Ugolkov AV, Yuuki K, Tsukigi M, Motoyama T, Tomita Y. The enhancer of zeste homolog 2 (EZH2), a potential therapeutic target, is regulated by miR101 in renal cancer cells. Biochem Biophys Res Commun. 2012; 422:607-614.

50. Qazi AM, Gruzdyn O, Semaan A, Seward S, Chamala S, Dhulipala V, Sethi S, Ali-Fehmi R, Philip PA, Bouwman DL, Weaver DW, Gruber SA, Batchu RB. Restoration of E-cadherin expression in pancreatic ductal adenocarcinoma treated with microRNA-101. Surgery. 2012; 152:704-711; discussion 711-703.

51. Liu X, Zou L, Zhu L, Zhang H, Du C, Li Z, Gao C, Zhao X, Bao S, Zheng H. miRNA mediated up-regulation of cochaperone p23 acts as an anti-apoptotic factor in childhood acute lymphoblastic leukemia. Leuk Res. 2012; 36:1098-1104.

52. Luo C, Merz PR, Chen Y, Dickes E, Pscherer A, Schadendorf D, Eichmuller SB. MiR-101 inhibits melanoma cell invasion and proliferation by targeting MITF and EZH2. Cancer Lett. 2013; 341:240-247.

53. Song B, Wang Y, Xi Y, Kudo K, Bruheim S, Botchkina GI, Gavin E, Wan Y, Formentini A, Kornmann M, Fodstad O, $\mathrm{Ju}$ J. Mechanism of chemoresistance mediated by miR-140 in human osteosarcoma and colon cancer cells. Oncogene. $2009 ; 28: 4065-4074$

54. Zhang Y, Eades G, Yao Y, Li Q, Zhou Q. Estrogen receptor alpha signaling regulates breast tumor-initiating cells by down-regulating miR-140 which targets the transcription factor SOX2. The Journal of biological chemistry. 2012; 287:41514-41522.
55. Yang H, Fang F, Chang R, Yang L. MicroRNA-140-5p suppresses tumor growth and metastasis by targeting transforming growth factor beta receptor 1 and fibroblast growth factor 9 in hepatocellular carcinoma. Hepatology. 2013; 58:205-217.

56. Yuan Y, Shen Y, Xue L, Fan H. miR-140 suppresses tumor growth and metastasis of non-small cell lung cancer by targeting insulin-like growth factor 1 receptor. PloS one. 2013; 8:e73604.

57. Tsuno S, Wang X, Shomori K, Hasegawa J, Miura N. HsamiR-520d induces hepatoma cells to form normal liver tissues via a stemness-mediated process. Sci Rep. 2014; $4: 3852$.

58. Kim TH, Kim YK, Kwon Y, Heo JH, Kang H, Kim G, An HJ. Deregulation of miR-519a, 153, and 485-5p and its clinicopathological relevance in ovarian epithelial tumours. Histopathology. 2010; 57:734-743.

59. Anaya-Ruiz M, Bandala C, Perez-Santos JL. miR-485 acts as a tumor suppressor by inhibiting cell growth and migration in breast carcinoma T47D cells. Asian Pac J Cancer Prev. 2013; 14:3757-3760.

60. Li QQ, Chen ZQ, Cao XX, Xu JD, Xu JW, Chen YY, Wang WJ, Chen Q, Tang F, Liu XP, Xu ZD. Involvement of NF-kappaB/miR-448 regulatory feedback loop in chemotherapy-induced epithelial-mesenchymal transition of breast cancer cells. Cell Death Differ. 2011; 18:16-25.

61. Li Q, Yao Y, Eades G, Liu Z, Zhang Y, Zhou Q. Downregulation of miR-140 promotes cancer stem cell formation in basal-like early stage breast cancer. Oncogene. 2014; 33:2589-2600.

62. Mayr C, Bartel DP. Widespread shortening of 3'UTRs by alternative cleavage and polyadenylation activates oncogenes in cancer cells. Cell. 2009; 138:673-684.

63. Bartel DP. MicroRNAs: Target Recognition and Regulatory Functions. Cell. 2009; 136:215-233.

64. Griffiths-Jones S, Saini HK, van Dongen S, Enright AJ. miRBase: tools for microRNA genomics. Nucleic Acids Res. 2008; 36:D154-158.

65. Van Peer G, Lefever S, Anckaert J, Beckers A, Rihani A, Van Goethem A, Volders PJ, Zeka F, Ongenaert M, Mestdagh P, Vandesompele J. miRBase Tracker: keeping track of microRNA annotation changes. Database. 2014; 2014. doi:10.1093/database/bau080.

66. Krek A, Grun D, Poy MN, Wolf R, Rosenberg L, Epstein EJ, MacMenamin P, da Piedade I, Gunsalus KC, Stoffel M, Rajewsky N. Combinatorial microRNA target predictions. Nat Genet. 2005; 37:495-500.

67. Lewis BP, Burge CB, Bartel DP. Conserved seed pairing, often flanked by adenosines, indicates that thousands of human genes are microRNA targets. Cell. 2005; 120:15-20.

68. Betel D, Koppal A, Agius P, Sander C, Leslie C. Comprehensive modeling of microRNA targets predicts functional non-conserved and non-canonical sites. Genome Biol. 2010; 11:R90. 
69. John B, Enright AJ, Aravin A, Tuschl T, Sander C, Marks DS. Human MicroRNA targets. PLoS Biol. 2004; 2:e363.

70. Betel D, Wilson M, Gabow A, Marks DS, Sander C. The microRNA.org resource: targets and expression. Nucleic Acids Research. 2008; 36:D149-D153.

71. Maragkakis M, Alexiou P, Papadopoulos GL, Reczko M, Dalamagas T, Giannopoulos G, Goumas G, Koukis E, Kourtis K, Simossis VA, Sethupathy P, Vergoulis T, Koziris N, Sellis T, Tsanakas P, Hatzigeorgiou AG. Accurate microRNA target prediction correlates with protein repression levels. BMC Bioinformatics. 2009; 10:295.
72. Wang X. miRDB: a microRNA target prediction and functional annotation database with a wiki interface. RNA. 2008; 14:1012-1017.

73. Yang J-H, Li J-H, Shao P, Zhou H, Chen Y-Q, Qu L-H. starBase: a database for exploring microRNA-mRNA interaction maps from Argonaute CLIP-Seq and Degradome-Seq data. Nucleic Acids Research. 2011; 39:D202-D209.

74. Barata JT, Cardoso AA, Nadler LM, Boussiotis VA. Interleukin-7 promotes survival and cell cycle progression of T-cell acute lymphoblastic leukemia cells by downregulating the cyclin-dependent kinase inhibitor p27(kip1). Blood. 2001; 98:1524-1531. 